\title{
Parameter estimation of height-diameter relationships of Gmelina arborea Roxb. (Family Verbenaceae)
}

\author{
${ }^{1}$ Oyamakin S. O, ${ }^{2}$ Fajemila A. D. and ${ }^{2}$ Abdullateef S. \\ ${ }^{1}$ Department of Statistics, University of Ibadan \\ ${ }^{2}$ Forestry Research Institute of Nigeria
}

\begin{abstract}
Measuring the height of a tree like Gmelina Arborea takes longer than measuring its diameter at breast height and often only the heights of a subset of trees of known diameter are measured in the forest inventories. Since trees with the same diameter are not usually of the same height, even within the same stand, a simultaneous equation techniques and multiple regression equation was used to fit the height-diameter data obtained from the Gmelina Arborea Plantation at Federal College of Forestry, Ibadan. This approach mimics the natural variability of height/dbh and therefore provides more realistic height/dbh predictions with the multiple regressions while the simultaneous equation techniques failed due to poor fit.
\end{abstract}

Keywords: Gmelina arborea, height, dbh, simultaneous, regression, forest Inventory

\section{INTRODUCTION}

Gmelina arborea Roxb. (Family Verbenaceae) is a fast growing tree frequently planted in plantations to produce wood for light construction, crafts, decorative veneers, pulp, fuel, and charcoal? The species is also planted in taungya systems with short-rotation crops and as a shade tree for coffee and cacao. It is commonly called gmelina and white beech (English), melina (Spanish), gamar in Bangladesh, melina/gambar in India, gemelina in Indonesia, yemane in Philippines and soh in Thailand, and it has many regional names (Brandis 1906, F/FRED 1994). Gmelina arborea is found in rainforest as well as dry deciduous forest and tolerates a wide range of conditions from sea level to $1200 \mathrm{~m}$ elevation and annual rainfall from 750 to $5000 \mathrm{~mm}$. It grows best in climates with mean annual temperature of $21-28^{\circ} \mathrm{C}$ (Jensen 1995). Gmelina grows best on deep, welldrained, base-rich soils with $\mathrm{pH}$ between 5.0 and 8.0. Growth is poor on thin, highly leached acid soils (F/FRED 1994).
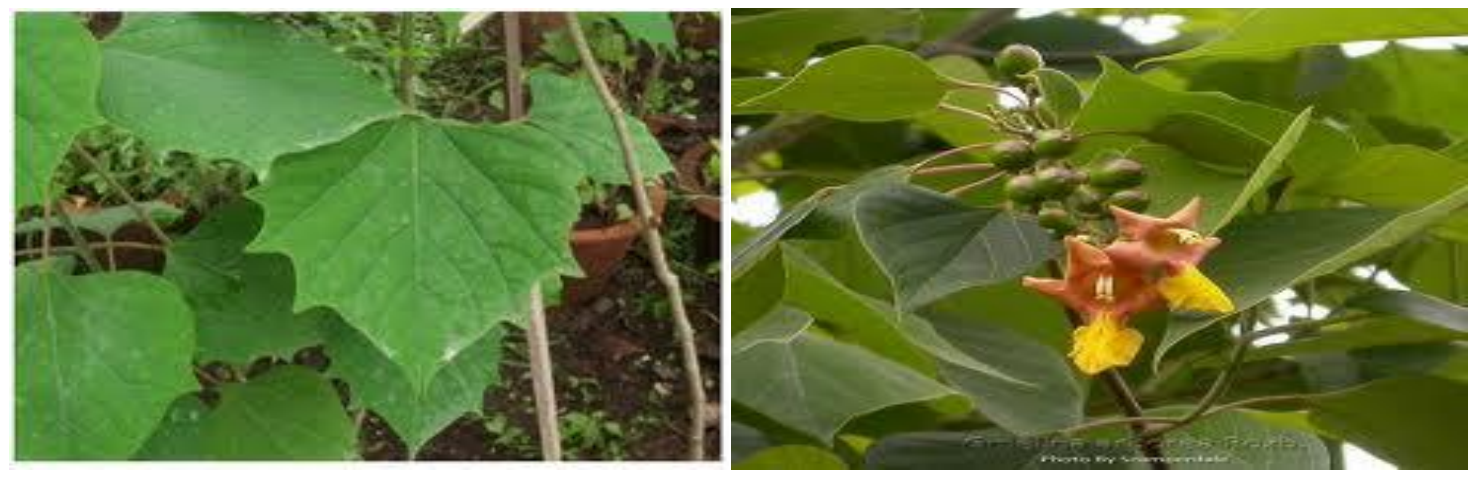

Fig. 1: Gmelina Arborea during its flowering period

Gmelina arborea is a medium-sized deciduous tree up to $40 \mathrm{~m}$ tall and $140 \mathrm{~cm}$ in diameter, but usually smaller than this (Jensen 1995). The tree form is fair to good, with 6-9 m of branchless, often crooked trunk and a large, low-branched crown. The bark is thin and gray. Leaves are simple, opposite, more or less heart-shaped, $10-25 \mathrm{~cm}$ long, and $5-18 \mathrm{~cm}$ wide. The yellow or brown flowers are arranged in panicled cymes 15-30 cm long, which appear after leaf-fall. The trumpet-shaped flowers are $4 \mathrm{~cm}$ long and are hairy and short-stalked. The fruit is a drupe 2-2.5 cm long and contains 1-4 seeds (Khan and 
Agric. Biol. J. N. Am., 2013, 4(4): 468-475

Alam 1996). The number of seeds per kilogram varies from 700-1400 (Evans 1982) to 2500 (Katoch 1992).

A casual look at the published empirical works in life sciences reveals that many relationships are of the single equation type. In such models, one variable \{the dependent variable $\mathrm{Y}\}$ is expressed as a linear function of one or more other variables the explanatory variables X's\}. An implicit assumption is that the cause and effect relationship, if any, between $Y$ and the X's is unidirectional. The explanatory variables are the cause and the dependent variable is the effect. However, there are situations where there is a two-way or simultaneous relationship between $Y$ and \{some of the $X$ 's which makes the distinction between the dependent and explanatory variables of dubious value. It is better to lump together a set of variables that can be determined simultaneously by the remaining set of variables - precisely what is done in simultaneous equation models. In such models, there is more than one equation - one for each of the mutually or jointly dependent or endogenous variables. And unlike the single equation models, in the simultaneous equation models, one may not estimate the parameters of a single equation without taking into account information provided by the other equation in the system.

In a simultaneous equation system, variables that appear only on the right hand side of the equality sign are called exogenous or predetermined variables. They are truly independent or non-stochastic because they remained fixed. Variables that appear on the right hand side and also have their own equations are referred to as endogenous variables. Unlike exogenous variables, endogenous variables change value as the simultaneous system of the equations grinds out equilibrium solution. They are endogenous variables because their values are determined within the system of the equations.

As a consequence of the endogenous variables appearing as explanatory variables, such an endogenous explanatory variables becomes stochastic and is usually correlated with the disturbance term of the equation in which it appears as an explanatory variable. In this situation, the classical ordinary least squares (OLS) method may not be applied because the estimators thus obtained are not consistent and that is, they do not converge to their true population values no matter how large the sample size. This is simultaneity bias.

When running an OLS regression, we assume all the explanatory variables are exogenous. In reality this is not always the case, some of the variables may be endogenous, this causes inconsistency in the estimator. i.e. the explanatory variable and error term are correlated, producing a non-BLUE estimator. One simple example is the Keynesian consumption function

\section{MATERIALS \& METHOD}

The choice of estimation method depends also on whether we are interested in the values of the structural parameters or the reduced form coefficients. Also, multiple regression analysis will be carried out on the five variables we are studying i.e Height and Diameter of Gmelina Arborea obtained in 2011, 2008 and 2004 from the Gmelina Arborea Plantation of the Federal College of Forestry, Ibadan.

Consider the models below:

$$
\begin{aligned}
& Y_{t 1}=\beta_{21} Y_{t 2}+\gamma_{11} X_{t 1}+\gamma_{21} X_{t 2}+u_{t 1} \\
& Y_{t 2}=\beta_{12} Y_{t 1}+\gamma_{12} X_{t 1}+\gamma_{32} X_{t 3}+u_{t 2}
\end{aligned}
$$

Where, $Y_{t 1} \& Y_{t 2}$ (Height2011 \& Dbh2011) are the endogenous variables. $X_{\mathrm{t} 1}, X_{\mathrm{t} 2} \& \mathrm{X}_{\mathrm{t} 3}$ (Height2008, Dbh2008 \& Height2004) are the exogenous variables and $U_{t 1} \& U_{t 2}$ are the disturbance terms.

Identification is a two-step process. The order or necessary condition which gives preliminary verdict, and the rank condition or sufficient condition which gives the full verdict.

Recall equation 1 ;

\section{First step- the order condition}

This involves using the order condition to determine whether the equation under investigation is justidentified or over-identified.

The equations can be rewritten as follows

$$
\begin{aligned}
& -Y_{t 1}=\beta_{21} Y_{t 2}+\gamma_{11} X_{t 1}+\gamma_{21} X_{t 2}+u_{t 1} \\
& \beta_{12} Y_{t 1}=Y_{t 2}+\gamma_{12} X_{t 1}+\gamma_{32} X_{t 3}+u_{t 2}
\end{aligned}
$$

Let $G$ and $K$ respectively be the number of endogenous and predetermined variables in the model. Let $\mathrm{g}$ and $\mathrm{k}$ be the corresponding number of endogenous and predetermined variables in the equation under consideration. If $K-k=g-1$, the equation may be over-identified but if $K-k<g-1$, the equation is said to be unidentified.

In our model, for equation 1 (2)

$\mathrm{G}=2, \mathrm{~K}=3, \mathrm{~g}=2$, and $\mathrm{k}=2$ 
$K-k=g-1$ i.e. $3-2=2-1=1$, the equation may be just identified

For equation 2 (2), $\mathrm{G}=2, \mathrm{~K}=3, \mathrm{~g}=2, \mathrm{k}=2$.

$K-k=g-1$ i.e. $3-2=2-1=1$, the equation may be just identified.

\section{Second step - the rank condition}

Here, if the rank of $A \varnothing>\mathrm{G}-1$, where $A$ is the matrix of constants and $\varnothing$ is the identity matrix, then the equation is over identified, if $A \varnothing=\mathrm{G}-1$, it is just identified, but if $A \varnothing<\mathrm{G}-1$, it is unidentified.

From equation 3.1.1

$$
A=\left(\begin{array}{ccccc}
-1 & \beta_{21} & \gamma_{11} & \gamma_{21} & 0 \\
\beta_{12} & -1 & \gamma_{12} & 0 & \gamma_{32}
\end{array}\right)
$$

$\Gamma_{22}=0$, since there is one zero restriction, $\varnothing$ has 1 column which has " 1 " in the 5 th row i.e.

$$
\begin{aligned}
& \Phi=\left(\begin{array}{l}
0 \\
0 \\
0 \\
0 \\
1
\end{array}\right) \\
& A \Phi=\left(\begin{array}{ccccc}
-1 & \beta_{21} & \gamma_{11} & \gamma_{21} & 0 \\
\beta_{12} & -1 & \gamma_{12} & 0 & \gamma_{32}
\end{array}\right)\left(\begin{array}{l}
0 \\
0 \\
0 \\
0 \\
1
\end{array}\right) \\
& \left(\begin{array}{l}
0 \\
\gamma 32
\end{array}\right) \text {, the rank } \rho(A \Phi)=1 \text {, this is compared with } \\
& \mathrm{G}-1=>2-1=1 \text { since } \rho(A \Phi)=G-1 \text {, the equation is }
\end{aligned}
$$

$$
\begin{gathered}
A=\left(\begin{array}{ccccc}
-1 & \beta_{21} & \gamma_{11} & \gamma_{21} & 0 \\
\beta_{12} & -1 & \gamma_{12} & 0 & \gamma_{32}
\end{array}\right) \\
\Gamma_{31}=0 \text { and as before we have }
\end{gathered}
$$

$$
\Phi=\left(\begin{array}{l}
0 \\
0 \\
0 \\
1 \\
0
\end{array}\right)
$$

Hence, $A \Phi=\left(\begin{array}{ccccc}-1 & \beta_{21} & \gamma_{11} & \gamma_{21} & 0 \\ \beta_{12} & -1 & \gamma_{12} & 0 & \gamma_{32}\end{array}\right)\left(\begin{array}{l}0 \\ 0 \\ 0 \\ 1 \\ 0\end{array}\right)$
$\left(\begin{array}{l}\gamma_{21} \\ 0\end{array}\right)$ The rank $\rho(A \Phi)=1$ since $\rho(A \Phi)=G-1$,

the equation is just identified.

Therefore, the two equations above are exactly identified.

Having gotten the exogenous variables and endogenous variables, the next step is the estimation of the structural parameters so far we are already in possession of the three necessary variables which are the exogenous variables Xi's (i.e. Height2008 dbh2008 \& height2004) and endogenous variables Yi's (i.e. Height2011 \& dbh2011). Armed with this information, we then estimate the structural parameters of our model using a statistical software package called Time Series Processor (TSP) version 5.0. With Height2011 as dependent variable (Y) regressed on Xi's (i.e.Dbh2011 Height2008 dbh2008 \& height2004) and Dbh2011 as dependent variable (Y) regressed on Xi's (i.e. Height2011 Height2008 dbh2008 \& height2004), a multiple regression analysis was also carried out to compare the fit of the simultaneous equation models to the multiple linear regression. Analysis of variance was also carried out to check if there is difference between the mean of height and Dbh measured between 2004 and 2011.

\section{Results Discussion}

The results of our study on the parameter estimates using six estimators are presented in Appendix 2 using the following estimation techniques in estimating the parameter of our model.

1. Ordinary Least squares (OLS).

2. Indirect Least Squares or Reduced form (ILS).

3. Two Stage Least Squares estimation (2SLS).

4. Limited Information Maximum Likelihood (LIML).

5. Three Stage Least Squares estimation (3SLS).

6. Full Information Maximum Likelihood.

In theory and as confirmed by Johnson (1991), when an equation is just identified, estimates of the parameter obtained by 2SLS, 3SLS and LIML should be identical. The results obtained in this study (i.e. 
Appendix 1) show that 2SLS, 3SLS and LIML estimators yielded similar results while OLS, ILS and FIML yielded results that are clearly different from them. Consequently, the effect of the predictors shall be studied with respect to their ability in explaining the variation in the current tree height. The results obtained showed a poor fit using simultaneous equation models hence, a multiple regression analysis is employed to fit the height/dbh model for Gmelina Arborea growth.

Table 1: Table showing the result of the multiple regression analysis with height2011 as the Response

\begin{tabular}{|l|r|r|r|r|}
\hline & \multicolumn{1}{|c|}{ Coefficients } & Standard Error & \multicolumn{1}{c|}{$\boldsymbol{t}$ Stat } & \multicolumn{1}{c|}{$\boldsymbol{P}$-value } \\
\hline Intercept & 8.356119128 & 2.270096027 & 3.680954034 & 0.00042307 \\
dbh2011 & -0.306055452 & 0.513445334 & -0.596081864 & 0.55282466 \\
height2008 & -1.372091043 & 0.833017414 & -1.647133685 & 0.10350293 \\
dbh2008 & 0.325634175 & 0.508718409 & 0.640106921 & 0.52395527 \\
height2004 & 1.908994541 & 0.862689778 & 2.212840108 & 0.02979508 \\
\hline
\end{tabular}

The regression equation is

height2011 = $8.36-0.306$ dbh2011 - 1.37 height2008 + 0.326 dbh2008

+1.91 height2004

Table 2: Table showing the result of the multiple regression analysis with Dbh2011 as the Response

\begin{tabular}{|l|r|r|r|r|}
\hline & \multicolumn{1}{|c|}{ Coefficients } & \multicolumn{1}{c|}{ Standard Error } & \multicolumn{1}{c|}{$\boldsymbol{t}$ Stat } & \multicolumn{1}{c|}{$\boldsymbol{P}$-value } \\
\hline Intercept & 2.241208403 & 0.474342139 & 4.724877297 & $9.85121 \mathrm{E}-06$ \\
height2011 & -0.014629709 & 0.02454312 & -0.59608186 & 0.55282466 \\
height2008 & -0.234951759 & 0.183330946 & -1.28157173 & 0.20374169 \\
dbh2008 & 0.984317179 & 0.013055444 & 75.39515419 & $2.31231 \mathrm{E}-75$ \\
height2004 & 0.247459698 & 0.192366579 & 1.286396522 & 0.202061915 \\
\hline
\end{tabular}

The regression equation is

$d b h 2011=2.24-0.0146$ height2011 - 0.235 height2008 + 0.984 dbh2008

+0.247 height2004

Table 3: Correlation matrix of Gmelina Arborea between 2004 and 2011

\begin{tabular}{|c|c|c|c|c|c|}
\hline & height2011 & $d b h 2011$ & height2008 & $d b h 2008$ & height2004 \\
\hline height2011 & 1 & & & & \\
\hline dbh2011 & 0.321061637 & 1 & & & \\
\hline height2008 & 0.477872686 & 0.5600727 & 1 & & \\
\hline dbh2008 & 0.326210836 & 0.995297907 & 0.564495101 & 1 & \\
\hline height2004 & 0.500262587 & 0.571308755 & 0.992575278 & 0.574212369 & 1 \\
\hline \multicolumn{3}{|c|}{$\begin{array}{l}\text { Since all the variables are correlated to some extent, } \\
\text { it is difficult to give a clear answer to whether } \\
\text { height } 2011 \text { is really related to dbh2011, or whether } \\
\text { the observed correlation between the variables arises } \\
\text { from the relationships of height } 2011 \text { to dbh2011, } \\
\text { height } 2008 \text {, dbh2008 and height } 2004 \text {. In trying to }\end{array}$} & \multicolumn{3}{|c|}{$\begin{array}{l}\text { disentangle the relationships involved in a set of } \\
\text { variables, it is often helpful to calculate partial } \\
\text { correlation coefficients. Such coefficients measure } \\
\text { the strength of the linear relationship between two } \\
\text { continuous variables that cannot be attributed to one } \\
\text { or more confounding variables. }\end{array}$} \\
\hline
\end{tabular}


Table 4: Regression Statistics

\begin{tabular}{|l|c|}
\hline Multiple R & 0.527845828 \\
\hline R Square & 0.278621218 \\
Adjusted R Square & 0.24209571 \\
Standard Error & 3.984890949 \\
Observations & 84 \\
\hline
\end{tabular}

Table 5: Regression Statistics

\begin{tabular}{|l|c|}
\hline Multiple R & 0.995402084 \\
\hline R Square & 0.990825308 \\
Adjusted R Square & 0.990360766 \\
Standard Error & 0.871232813 \\
Observations & 84 \\
\hline
\end{tabular}

The model fit output consists of a model summary table ( See Table 4\&5) and an ANOVA table (See Table 6 \& 7). The former includes the multiple correlation coefficients, $R$, its square, $R^{2}$, and an adjusted version of this coefficient as summary measures of the model fit. The multiple correlation coefficient $R=0.53$ (height2011), 0.99 (dbh2011). The former indicates an average positive relationship between the observed height2011 and those predicted by the regression models while the later indicates that there is a very strong positive correlation between the observed dbh2011 and those predicted by the regression model. In terms of variability in observed height2011 and dbh2011 accounted for by our fitted model, this amounts to a proportion of $\mathrm{R}^{2}=0.278$ or $27.8 \%$ in the height 2011 while $R^{2}=0.995$ or $99.5 \%$ in the dbh2011 fit. Since by definition $R^{2}$ will increase when further terms are added to the models even if these do not explain variability in the height or dbh of Gmelina Arborea. The adjusted $R^{2}$ is an attempt at improved estimation of $R^{2}$ in the height and dbh modeling of Gmelina Arborea. The index is adjusted down to compensate for chance increases in $\mathrm{R}^{2}$, with bigger adjustments for larger set of explanatory variables (Der and Everitt, 2001).

Table 6: ANOVA Table for regression analysis of Gmelina Arborea with height2011 as response

\begin{tabular}{|l|r|r|r|r|r|}
\hline \multicolumn{7}{|l|}{ ANOVA } & $\boldsymbol{d}$ & \multicolumn{1}{|c|}{ S } & MS & $\boldsymbol{F}$ & Significance $\boldsymbol{F}$ \\
\hline & 4 & 484.518981 & 121.1297453 & 7.62812713 & $2.99802 \mathrm{E}-05$ \\
Regression & 79 & 1254.46911 & 15.87935587 & & \\
Residual & 83 & 1738.9881 & & & \\
Total & & & & \\
\hline
\end{tabular}

Table 7: ANOVA Table for regression analysis of Gmelina Arborea with Dbh2011 as response

\begin{tabular}{|l|r|r|r|r|r|}
\hline ANOVA & \multicolumn{5}{|c|}{} \\
\hline & $\boldsymbol{d} \boldsymbol{f}$ & \multicolumn{1}{|c|}{ SS } & \multicolumn{1}{|c|}{ MS } & \multicolumn{1}{|c|}{$\boldsymbol{F}$} & Significance $\boldsymbol{F}$ \\
\hline Regression & 4 & 6475.914841 & 1618.97871 & 2132.910786 & $1.33634 \mathrm{E}-79$ \\
Residual & 79 & 59.9646825 & 0.759046614 & & \\
Total & 83 & 6535.879524 & & & \\
\hline
\end{tabular}

The error term in multiple regression measure the difference between an individual heights/dbh of Gmelina Arborea and the mean height/dbh of Gmelina Arborea of the same specie of Gmelina height/dbh recorded at different year intervals. According to the regression model, the mean deviation is zero (positive and negative deviations cancel each other out). But the more variable the error the larger the absolute differences between the observed height/dbh and those expected. Table 4 \& 5 provide an estimate of the standard deviation of the error term. Here we estimate the mean absolute deviation as 3.98 meters for height and 0.871 centimeters for $\mathrm{dbh}$, which is small considering the observed height/dbh of Gmelina Arborea. 
Table 6 \& 7 presents the ANOVA tables, which present an F-test for the null hypothesis that none of the explanatory variables are related to Gmelina Arborea height/dbh increment, or in other words, that $\mathrm{R}^{2}$ is zero. Here we can clearly reject this null hypothesis $(F(4,79)=7.628$ (height) \& $F(4,79)=$ 2132.91 (dbh), $p<0.001$ ), and so we conclude that at least one of the predictors is related to the total height/dbh of Gmelina Arborea.

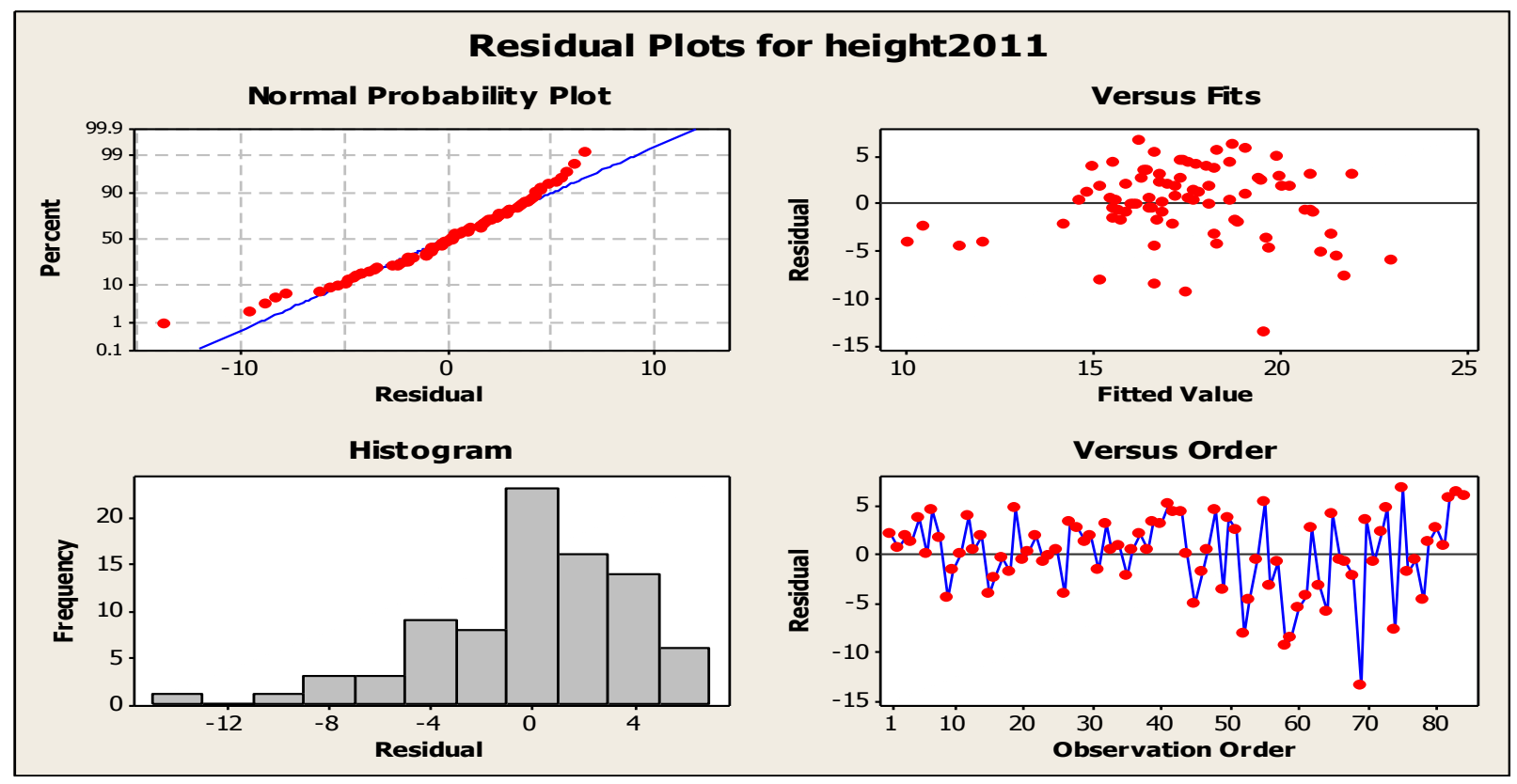

Fig 2: Residual plot of the Gmelina Arborea regression analysis with height2011 as response

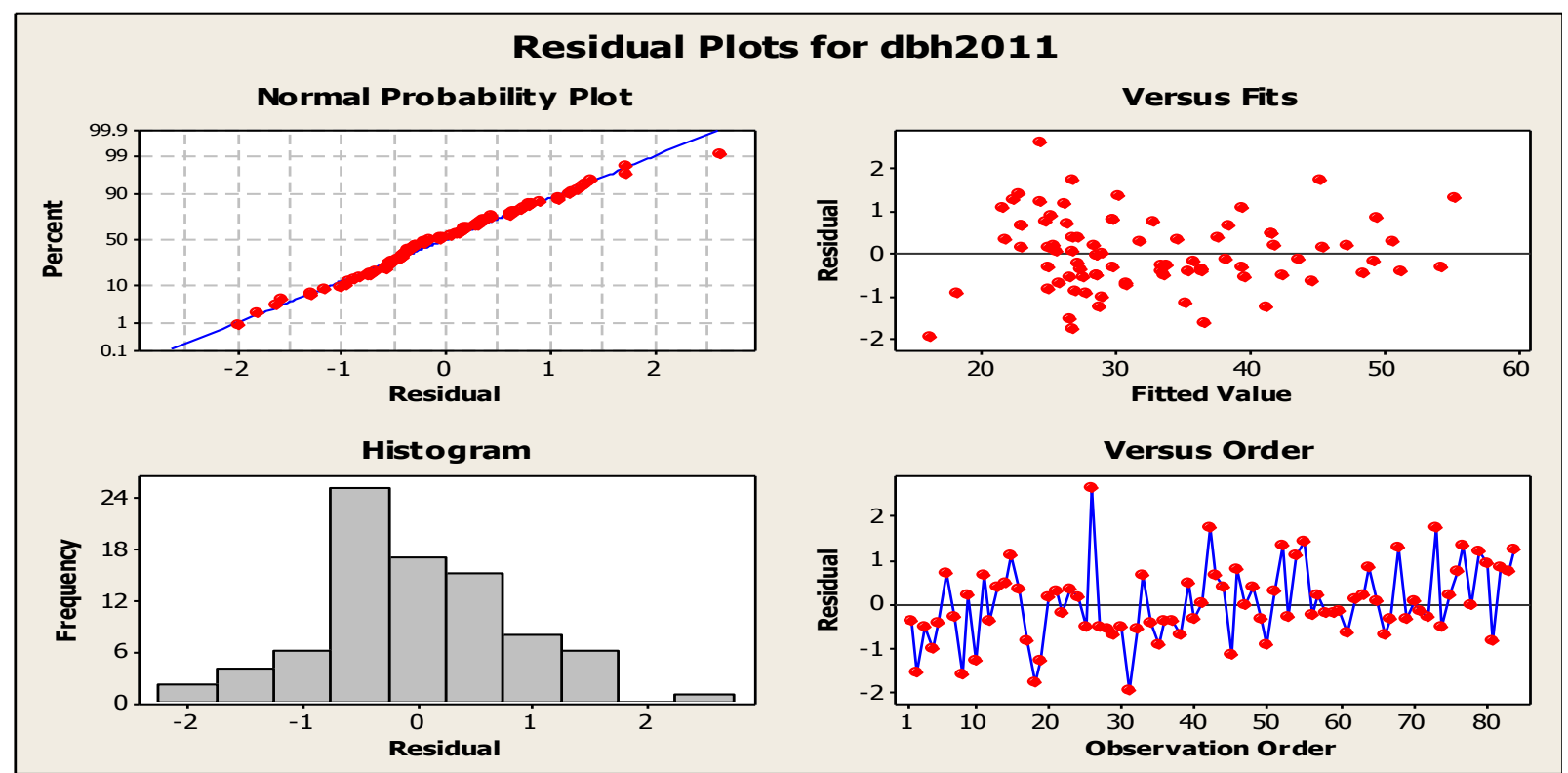

Fig 3: Residual plot of the Gmelina Arborea regression analysis with Dbh2011 as response 


\section{CONCLUSION}

The problems of estimating parameters and making the inference of equation confront researchers. In this study, efforts were made to solve these problems under different level of occurrence. Given the nature of biological phenomena, it is very much certain that some biological equation will not belong to a wider system of simultaneous equations or nonlinear equations.

Having arrived at a final multiple regression models for height/dbh data of Gmelina Arborea and the assumptions made in the modeling process. We can conclude that the multiple regression models have provided a good fit for the height/dbh of Gmelina Arborea using previously observed heights and $\mathrm{dbh}$ as predictors. Also, the model appears adequate in light of the data by producing good results for the fitted regression equation to be interpreted. The most useful approach for assessing these assumptions were examined using some form of residual from the fitted model along with some of the many other regression diagnostics. Residuals at their simplest are difference between the observed and fitted values of the response variable i.e. height/dbh. The following residual diagnostics are presented in Fig. 2 \& 3 above. Residual plot is a scatterplot of residuals against predicted values and these should lie around zero with the degree of scatter not varying systematically with the size of predicted values as we have in Fig. 3. Hence, the errors have the same variance (homogeneity), arise from a normal distribution and the relationship between each explanatory variable and the dependent variable is linear and the effects of several explanatory variables are additive.

\section{REFERENCES}

Adegbehin, J.O., J.O. Abayomi, and L. B. Nwaigbo. 1988. Gmelina arborea in Nigeria. Commonwealth Forestry Review, 67(2):159-166.

Alam, M.K., N.A. Siddiqi, and S. Das. 1985. Fodder trees of Bangladesh. Bangladesh Forest Research Institute, Chittagong, Bangladesh. 167 p.

Adejumobi, A. Adedayo (2006), "Robustness of Simultaneous Estimation Techniques to OverIdentified and Correlated Deviates". Ph.D Thesis, University of Ibadan.
Bryon, B.P. (1972), "Testing for Misspecification in Econometric Systems Using Full Information" Int. Econ. Rev, 12: 745-756

C. Nelson and Startz (1990), "The Distribution of the Instrumental Variables Estimator and its T-Ratio", Journal of Business, 63, 5125-5140.

Cragg, J.G. (1966), "On the sensitivity of Simultaneous equation Estimators to the Stochastic Assumptions of the Models", Journal of America Statistical Association, 61, 136-151.

Cragg, J.G. (1967), "On the Relative Small Sample Properties of Several Structural Equation Estimators", Econometrical, 35, 89-110.

Cragg, J.G. (1968), "Some Effects of Incorrect Specification on the Small Sampling Properties of several Simultaneous Equation Estimators", International Economic Review, Vol. 9, pp. 63-86.

Cumbustus M.J (2007), "Econometrics Methods and Applications", Lecture notes, Univeristy of Essex. Unpublished.

D. Hendry (1984), "Monte Carlo Experimentation in Econometrics", Handbook of Econometrics, Vol. 2, Z. Griliches and M.D. Intriligator. Elsevier, 944.

Davidson, J. 1985. Assistance to the forestry sector of Bangladesh. Species and sites-What to plant and where to plant. Field Doc. No. 5, UNDP/FAO/BGD/79/017. 50 p.

Denton, F.T and Kulper, J, "The effect of measurement errors on parameter estimates and forcasts", Rev. Econometrics and Statistics, vol 47 pp 198-206, 1995.

Dhrymes, P.J (1970), "Econometrics Statistical Foundations and Application", New York.

Evans, J. 1982. Plantation forestry in the tropics. Clarendon press, Oxford, UK. $472 \mathrm{p}$.

Fomby, T.B., Hill, R.C., and Johnson, H.B. (1984), "Advanced Econometrics Methods" New York: Springer-verleg

Forestry/Fuelwood Research and Development Project (F/FR ED). 1994. Growing multipurpose trees on small farms, module 9: Species fact sheets (2nd ed.). Bangkok, Thailand: Winrock International. $127 \mathrm{p}$.

Gallant, A.R and D.W. Jorgwsone. "Statistical Inference for a System of Simultaneous, Non-linear, Implicit Equations. The context of Instrumental Variable Estimation" J. Econometrics 11(1976), 275-302

Greene, W.H. (2003), "Basic Econometric Methods", $\left(5^{\text {th }}\right.$ Edition), Prentice hall.

Gujarati, D.N (2003), "Basic Econometric Methods", $\left(4^{\text {th }}\right.$ Edition) McGraw-Hill.

H. Wold and L. Jureen, "Demand Analysis", New York, John Wiley, 53. 
Hausman, J.A. (1978), "Specification Tests in Econometrics" Econometrics 46, 1251- 1271

Hendry, D.F. (1984), "Monte Carlo Experimentation in Econometrics", Handbook of Econometrics, Vol. 11. Edited by Z. Grilichesad, M.D. Intrilligator. Elseview science publishers B.V.

Jensen, M. 1995. Trees commonly cultivated in Southeast Asia; Illustrated field guide. RAP p. 93.

Publication: 1995/38, FAO, Bangkok, Thailand.

Johnston, J and Dinardo, J. (1998), "Econometric Methods", Fourth Edition, McGraw-Hill International.

Johnston, J. (1972), "Econometric Methods", Second Edition, McGraw-Hill International.

Judge, G. GR, C. Hill, H. Lufkerpolil and Tlee (1985), "The theory and practice of Econometrics $2^{\text {nd }}$ Edition, New York: Wiley.

Kennedy, P. (1985), "A Guide to Econometrics". Cambridge Massachusetts: The Mit Press.

Kmeta, JAM (1971), "Elements of Econometrics", New York, MacMillan Press Ltd.

Koutsoyeannis, A (1997), "Theory of Econometrics (2000) Edited by Macmillan Press Ltd.

L. Matyas and L. Lovrics (1991), "Missing Observations and panel Data- A Monte Carlo Analysis, "Economic Letters, 37, 39-44.

Lauridsen, E.B., E.D. Kjaer, and M. Nissen. 1995. Second evaluation of an international series of Gmelina provenance trials. DANIDA Forest Seed Centre. Humlebaek, Denmark. 120p.

Lawrence R. Klein (1974), "Revert-A Textbook of Econometrics", Second Edition, Prentice Hall, Englewood Cliffs NJ, pg 573-590.

Lea, J.D. and Shoukwiler, J.S (1988), "Misspecification in Simultaneous System: An Alternative Test and its Application to a Model of the Shinip Market. Southern Journal of Agricultural Economics.

Liu, T.C. (1960), "Under Identification, Structural Estimation and Forcasting". Econometrica, Vol. 28, pp 855-865.

Maddala, G.S. (2001), "Introduction to Econometrics", $2^{\text {nd }}$ Edition, Macmillan.

Nagar, A.L. (1959), "The Bias and Moment Matrix of the General-Class Estimators of the Parameters in Simultaneous Equations", Econometrica, Vol. 27, pp. 575-595.

Nagar, A.L. (1960) "A Monte Carlo Study of Alternative Simultaneous Equation Estimators", Econometrics 28, 573-590.

Oduntan, E.A (2004), "A Monte Carlo Study of the Problem of Multicollinearity in a simultaneous Equation Model" (Unpublished).
Olubusoye, O.E (2001), "Lecture notes on Econometrics", University of Ibadan (Unpublished).

Olubusoye, O.E (2008), "Evidence of variance covariance Matrix Sensitivity to correlated Normal Deviates". University of Ibadan (Unpublished).

Olubusoye, O.E. (2001), "Relative Sensitivity of Estimators of Simultaneous Equations to Violation of Mutual Independence of Random Deviates", Ph.D. Thesis, University of Ibadan.

Robert L. Basmann (1957), "A Generalized Classical Methods of linear Estimation of Coefficients in a Structural Equation". Econometrica Vol. 25, pp 7783.

T.W. Anderson and H. Rubin (1949), "Estimation of the Parameters of a Single Equation in a Complete System of Stochastic Equations", Annual Math. Statistics Vol. 20, pp46-63.

Quandt, R.E. (1962), "Some Small Sample Properties of Certain Structural Equation Estimators". Econometric Research Program, Princeton, Research Memorandum, No. 48.

Quandt, R.E. (1965), “On Certain Small Sample Properties of K-Class Estimators" International Economic Review, 6, 92-104.

S.O. Oyamakin (2011): "Height-diameter Relationship in Tree modeling using Simultaneous Equation Techniques in Correlated Random deviates" Journal of Modern Applied Statistical Methods, November 2011, Vol. 10, No. 2, 675 - 685.

S.O. Oyamakin (2011): " On performance of Simultaneous Equation Model Estimators Using Average Parameter Estimates in the presence of correlated Random Deviates" Asian Journal of Mathematics \& Statistics, 5: 39 - 49. DOI: 10.392/ajms.2012.39.49

URL: ttp://scialert.net/abstract/?doi=ajms.2012.39.49.

Summers, R. (1965), "A Capital Intensive Approach to the Small Sample Properties of Various Simultaneous Equation Estimators", conometrica, 33, 1-41.

Tifase, O.E. (2007), "Assessing the performance of Estimators of Simultaneous Equations Models using Monte Carlo approach, M.Sc. Thesis, University of Ibadan, Nigeria.

Troup, R.S. 1921. The silviculture of Indian trees. Clarendon Press, Oxford, UK. Vol. 2, p. 769-776.

Wagner, H.M. (1958), "A Monte Carlo Study of Estimators of Simultaneous Linear Structural Equations", Econometrica, 26, 127-133.

Wong, C.Y., and N. Jones. 1986. Improving tree form through vegetative propagation of Gmelina arborea. Commonwealth Forestry Review, 65(4):321-324. 